\title{
Earth Science
}

Information System (ESIS)

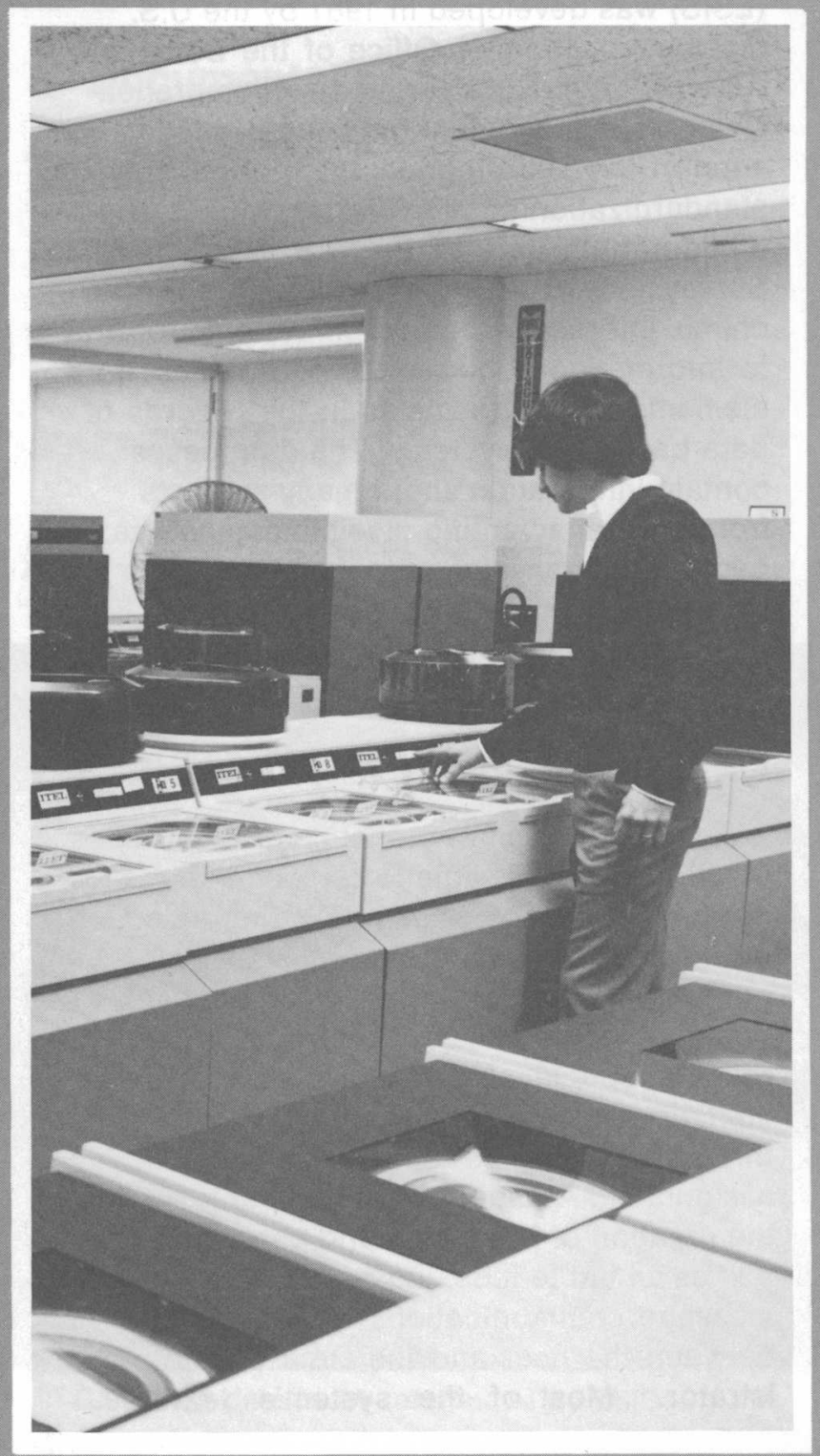




\section{Earth Science Information System (ESIS)}

\section{Historical Background}

The Earth Science Information System (ESIS) was developed in 1981 by the U.S. Geological Survey's Office of the Data Administrator. ESIS serves as a comprehensive data management facility designed to support the coordination, integration, and standardization of scientific, technical, and bibliographic data of the U.S. Geological Survey (USGS). ESIS provides, through an online interactive computer system, referral to information about USGS data bases, data elements which are fields in the records of data bases, and systems. The data bases contain information about many subjects from several scientific disciplines such as: geology, geophysics, geochemistry, hydrology, cartography, oceanography, geography, minerals exploration and conservation, and satellite data sensing.

\section{Characteristics}

An important characteristic of ESIS is ease of use. The user is able to select functions to perform by means of menus listing selection options and is guided step-by-step by prompting, instructions, and detailed explanations. Preformated reports simplify retrieval specification. Security is assured by limitations of access and updating privileges through user registration and password assignment. Additional special features allow the creation of key words and phrases in data text as an aid to indexing and to allow for message communications via the system between the user and the Data Administrator. Most of the system's features may be used without any programming knowledge.

The system contains an inventory of data bases, a data element dictionary, and an inventory of automated systems:

Data Base Inventory (DBI), first published as USGS Circular 817, describes USGS data bases in terms of these characteristics:

$\begin{array}{ll}\text { Data Base Name } & \text { Data Base Status } \\ \text { and Acronym } & \text { Users } \\ \text { Data Base Type } & \text { Availability } \\ \text { System Name } & \text { Type of Access Method } \\ \text { and Acronym } & \text { Output Media } \\ \text { Division } & \text { Storage Media } \\ \text { Contact Person, Address, } & \text { Number of Records } \\ \text { Phone } & \text { Bytes Per Record } \\ \text { Subject Coverage } & \text { Predicted Growth Rate } \\ \text { Keywords } & \text { Computer Type } \\ \text { Geographic Coverage } & \text { Computer Location } \\ \text { Geographic Area } & \text { Languages } \\ \text { Spatial Data Type } & \text { Data Base Management } \\ \text { Coordinate System } & \text { System } \\ \text { Data Source } & \text { Data Base Description } \\ \text { Data Structure } & \text { Documentation } \\ \text { Begin Time Span } & \text { Date Submitted } \\ \text { End Time Span } & \text { Comments }\end{array}$

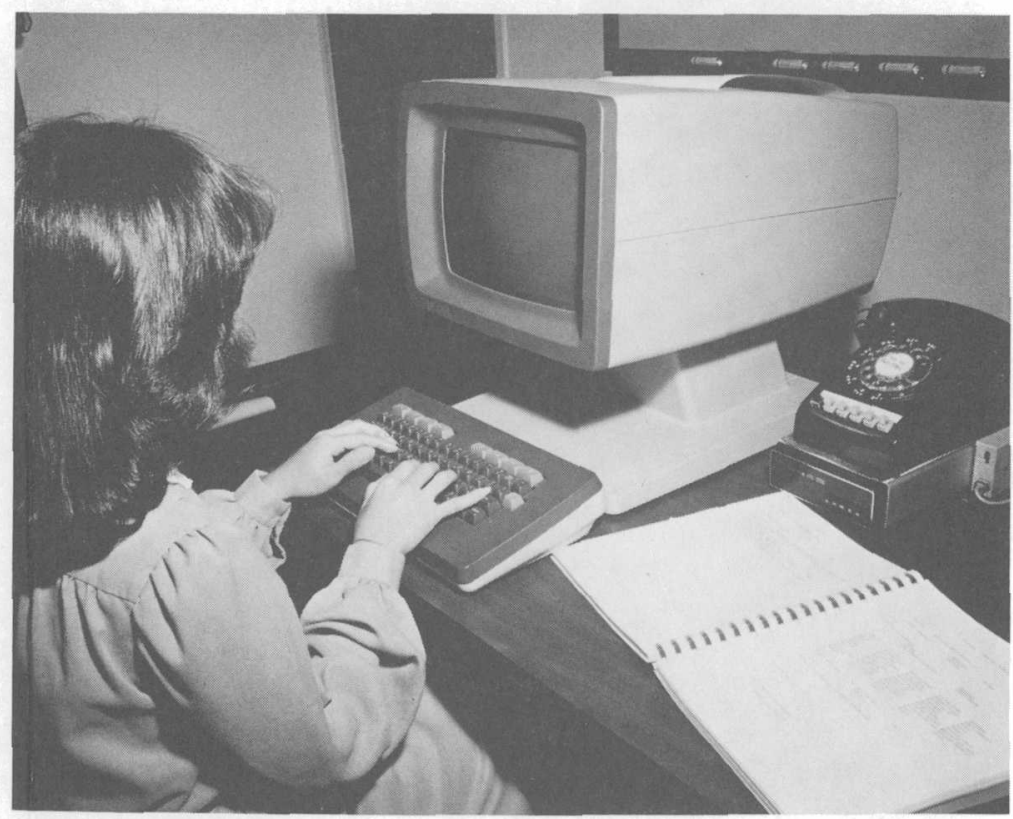

Using the system is easy. 
Data Element Dictionary (DED) describes every data element in each data base in terms of these attributes:

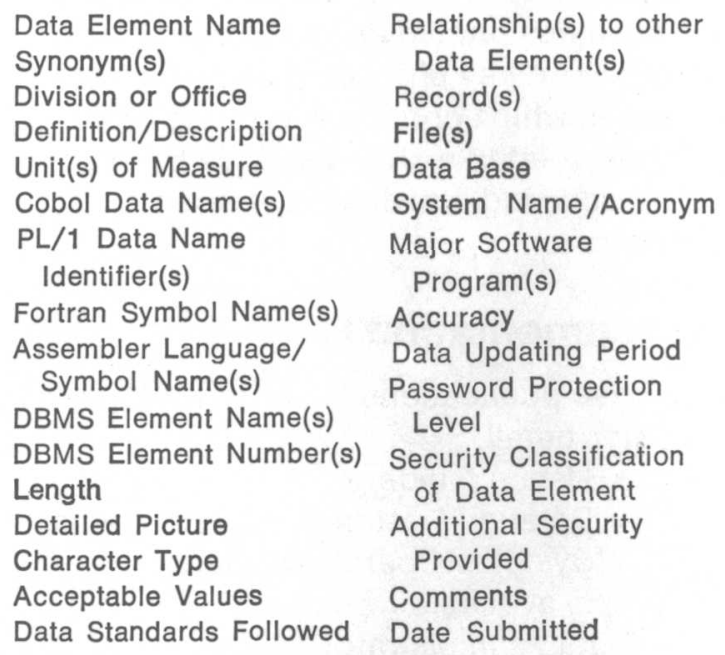

Inventory of Automated Systems (IAS) describes those systems which access USGS data bases in these terms:

\begin{tabular}{|c|c|}
\hline System Name & Type of Access Method \\
\hline Acronym & Frequency of Data Input \\
\hline Division & Frequency of Data \\
\hline Application Category & Output \\
\hline $\begin{array}{l}\text { Data Base Accessed by } \\
\text { System }\end{array}$ & $\begin{array}{l}\text { Computer Type } \\
\text { Computer Location }\end{array}$ \\
\hline $\begin{array}{l}\text { Contact Person, Address, } \\
\text { Phone }\end{array}$ & $\begin{array}{l}\text { Memory Required } \\
\text { (K Bytes) }\end{array}$ \\
\hline Description of System & Peripheral Devices \\
\hline Date Implemented & Operating System \\
\hline $\begin{array}{l}\text { Date of Last Major Modi- } \\
\text { fication }\end{array}$ & $\begin{array}{l}\text { Vendor or Commercially } \\
\text { Developed Software or }\end{array}$ \\
\hline $\begin{array}{l}\text { Expected Life of Appli- } \\
\text { cation }\end{array}$ & $\begin{array}{l}\text { DBMS } \\
\text { USGS Software }\end{array}$ \\
\hline Other Systems Used in & Language(s) \\
\hline Conjunction with this & Input Media \\
\hline System & Output Media \\
\hline Application Status & Input Location \\
\hline $\begin{array}{l}\text { Estimated Annual Operat- } \\
\text { ing Costs }\end{array}$ & $\begin{array}{l}\text { System Security } \\
\text { Comments }\end{array}$ \\
\hline Users & Date Submitted \\
\hline
\end{tabular}

\section{Functions of ESIS}

ESIS offers several capabilities supported by menus for option selection and step-by-step instructions to initiate these functions:

Online Data Entry allows terminal entry of data base, data element, and system data in full screen or line-by-line teletype (TTY) mode.

Online Data Update allows add, modify, and delete capability by terminal.

Batch Data Entry is used for high volume data entry in batch mode.

Standard Queries have access to a series of preformated outputs initiated by prompted parameters.

Ad Hoc Queries is a capability for development of unique queries using the Model 204 Query Language which provides full Boolean capability.

Message Facility is a means of communicating between user and the Data Administrator through ESIS.

Keyword Reference Facility automatically indexes several text fields into key or subject words and phrases for retrieval purposes and reference.

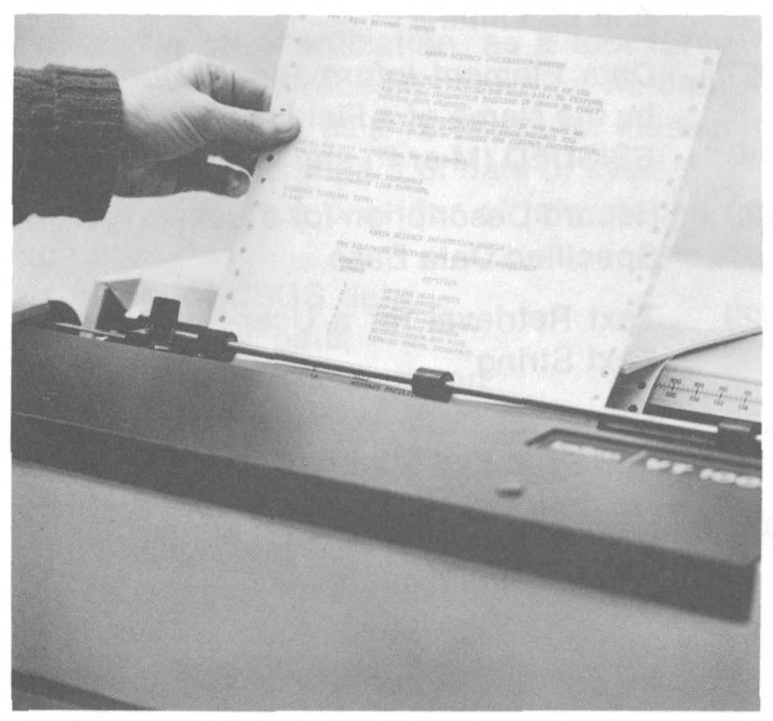


Authorization and Move is a tool of the Data Administrator for filing data attributes which have been officially sanctioned by the standardization process of the USGS.

\section{The Standardization Process}

ESIS serves as a valuable reference for the standardization of data element names, definitions, and the particular codes or characters used to represent data.

The Data Administrator, concerned with the compatability of data and systems, directs the coordination of the standards ratification process at the USGS, which evaluates and selects names, definitions, and codes for official use by the earth-science community.

All data elements initially entering ESIS automatically become "proposed" candidates for standardization. After standardization, the Data Administrator uses an automated Authorization and Move function to create "master" names, descriptions, synonyms, lengths, detailed pictures, and character types.

\section{The Hardware/Software Environment}

ESIS is located on the AMDAHL V7 at the USGS National Center in Reston, Va. It can be accessed by any teletype (TTY) compatible terminal and can be updated, in a full screen mode, through a Datagraphix 132B terminal.

Software used by ESIS is provided by the Model 204 Data Base Management System developed by the Computer Corporation of America.

\section{ESIS Users-Four Categories}

In order to differentiate between users granted authority to change values and to perform other systems functions, a hierarchy of user types was established. The hierarchy, in ascending order, is listed below:

(1) General User may request a standard report or query, use the message facility and perform ad hoc queries.

(2) Contact Person has the privileges of a general user and may enter and update data for which this person is responsible.

(3) Division Contact has the privileges of a contact person but may enter and update data for all of the systems, data bases, and data elements of an entire Division or Office.

(4) Data Administrator possesses all system capabilities including Authorization and Move.

\section{How To Be Registered as an ESIS User}

Anyone may become an authorized ESIS user simply by contacting the Office of the Data Administrator at the address listed on the back page of this publication.

\section{ESIS Has Many Uses}

Among its many uses, ESIS can be used as a guide for standardization, as a tool for system design or redesign through its data dictionary aspects, as a yardstick for measuring the economic impact of data or system changes, and as a provider of information such as:

- Users of USGS data,

- Sources of data,

- Available documentation,

- Computer hardware and software resources,

- Data that needs standardization or redesign, and

- Volumes of data available. 


\section{The Following Queries Are Currently Available}

Query

Number

Q1 Data Base Names and Descriptions for a User-Specified Division

Q2 Data Element Information for a User-Specified Data Base Name and Data Element Name or Synonym

Q3 Automated System Information Selected by the Name of a Field in the ESISIAS and its Value

Q4 Data Element Information for a User-Specified Data Element Name or Synonym

Q5 Data Base and Data Element Information for a User-Specified Data Base Name

Q6 Data Base Name and Division by the Name of a Field in the ESISDBI and its Value
Data Base Identification for a UserSpecified System Name from the ESISDBI

Data Element Names and Descriptions for a User-Specified Data Base Name or Acronym

Computer Program Identification for a User-Specified Data Base Name and Data Element Name

Record Description for a UserSpecified Record Name and Data Base Name or Acronym

Data Base Counts for UserSpecified Data Base Type and Division

Keyword Index Search for Specific Keyword/Phrase

Keyword Index Search for Specified Alphabetic Range

Keyword Index Search for Specified String

Names of Systems, Data Bases, or Data Elements in ESIS

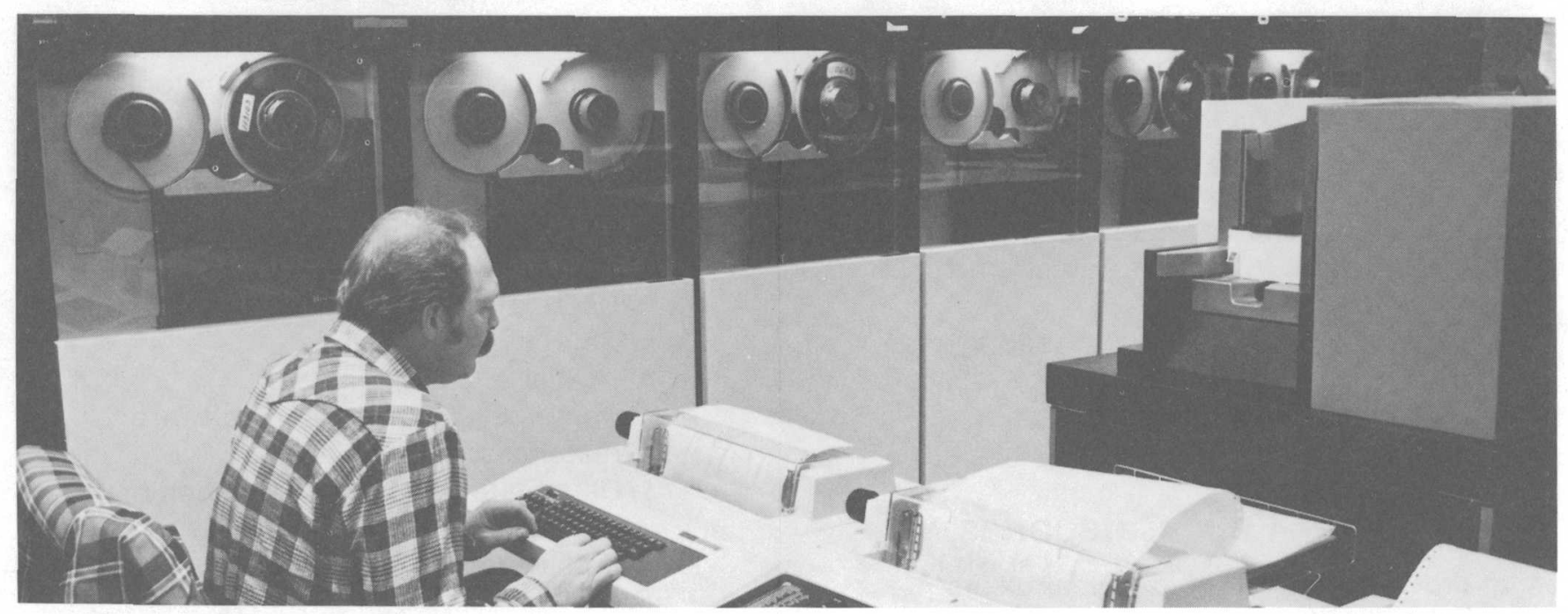

The large volumes of ESIS data are securely protected. 
Q16 Data Element and DB Names for Specified Alphabetic Range

Q17 Contents of any one Field in any one File

Q18 Data Element and Data Base Names with Security Level

Q19 Standardized Data Element Information

Q20 Original Data Element Name(s) of Standard Elements

Q21 Boolean Search of Keywords/ Phrases

Q22 Names of Systems or Data Bases on Specified Computer Type

Q23 Names of Systems or Data Bases at a Specified Location

Q24 Names of Data Bases Having a Specified Data Structure

Q25 Names of Data Bases and Their Contact Persons Using a Specified DBMS

Q26 Data Base Information Selected by the Name of a Field in the ESISDBI and its Value

Q27 Data Element Information Selected by the Name of a Field in the ESISDED ( $M$ or $P)$ and its Value

Q28 Record Description for a UserSpecified Data Base

Q29 Text Retrieval for a User-Specified Text String

Q30 Names of Data Elements Adhering to a Specified Standard

Q31 Names of Data Bases on More than one Computer

\section{Keyword Reference Facility}

Much of the data in the system is in free or text form. This is automatically scanned and may be designated as key words or two- or three-word key phrases. The fields and records which contain these, and other closely related words, can then be easily retrieved and used as a reference to other information.

\section{Documentation}

These publications describe ESIS in greater detail:

- User's Guide,

- Detailed Design Specifications, and

- Systems Operations Guide.

They are available from:

Data Administrator

U.S. Geological Survey

115 National Center

Reston, VA 22092

Telephone: (703) 860-6086

FTS: $928-6086$

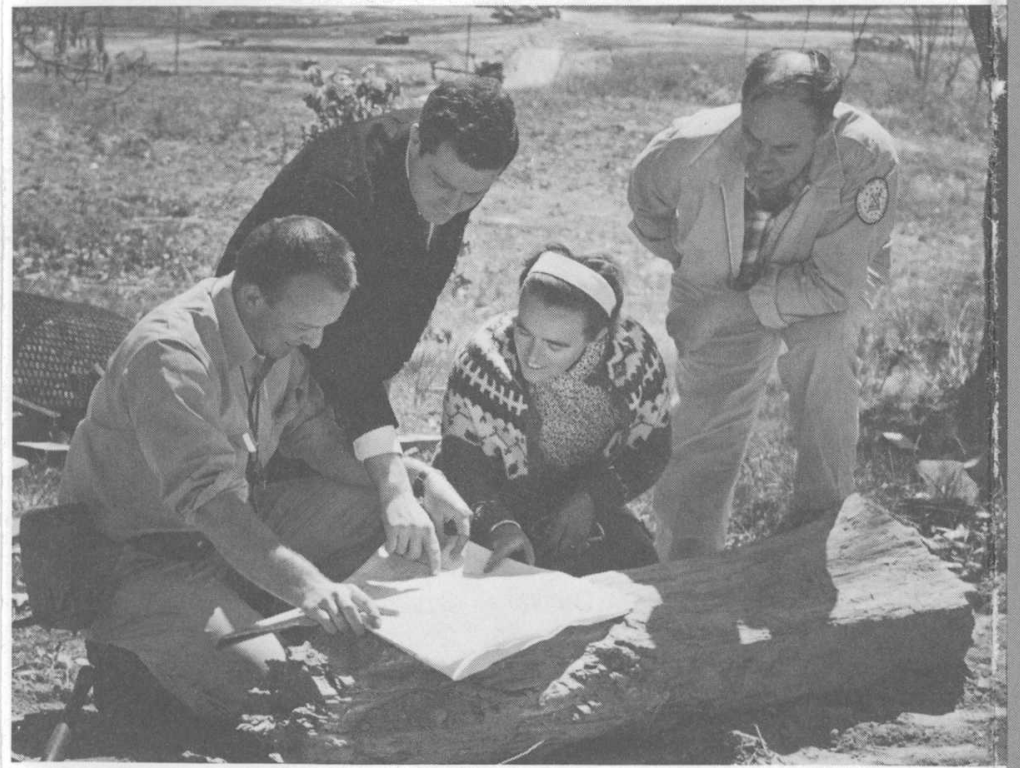

Gathering data to be referenced by ESIS. 